\title{
Evaluation of compliance to national nutrition policies in summer day camps
}

\author{
Falon Tilley ${ }^{1, *}$, Michael W Beets ${ }^{1,2}$, Sonya Jones ${ }^{2,3}$ and Gabrielle Turner-McGrievy ${ }^{2,3}$ \\ 'Department of Exercise Science, Arnold School of Public Health, University of South Carolina, 921 Assembly Street, \\ Columbia, SC 29208, USA: ${ }^{2}$ Center for Research in Nutrition and Health Disparities, University of South Carolina, \\ Columbia, SC, USA: ${ }^{3}$ Department of Health Education Promotion and Behavior, Arnold School of Public Health, \\ University of South Carolina, Columbia, SC, USA
}

Submitted 14 February 2013: Final revision received 10 April 2014: Accepted 6 May 2014: First published online 9 June 2014

\begin{abstract}
Objective: The National Afterschool Association (NAA) standards specify the role of summer day camps (SDC) in promoting healthy nutrition habits of the children attending, identifying foods and beverages to be provided to children and staff roles in promoting good nutrition habits. However, many SDC do not provide meals. Currently, national guidelines specifying what children are allowed to bring to such settings do not exist, nor is there a solid understanding of the current landscape surrounding healthy eating within SDC.

Design: A cross-sectional study design using validated measures with multiple observations was used to determine the types of foods and beverages brought to SDC programmes.

Setting: Four large-scale, community-based SDC participated in the study during summer 2011.

Subjects: The types of foods and beverages brought by children ( $n$ 766) and staff ( $n$ 87), as well as any instances of staff promoting healthy eating behaviours, were examined via direct observation over $27 \mathrm{~d}$. Additionally, the extent to which current foods and beverages at SDC complied with NAA standards was evaluated. Results: Less than half of the children brought water, $47 \%$ brought non- $100 \%$ juices, $4 \%$ brought soda, $4 \%$ brought a vegetable and $20 \%$ brought fruit. Staff foods and beverages modelled similar patterns. Promotion of healthy eating by staff was observed $<1 \%$ of the time.

Conclusions: Findings suggest that foods and beverages brought to SDC by children and staff do not support nutrition standards and staff do not regularly promote healthy eating habits. To assist, professional development, parent education and organizational policies are needed.
\end{abstract}

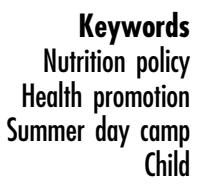

Over the three months of summer, children in the USA gain more weight than during the nine-month school year and this gain is exacerbated in minority children ${ }^{(1)}$. Children generally consume a higher-quality diet from school meal programmes, which often follow guidance similar to the Dietary Guidelines for Americans ${ }^{(2)}$, than they do when they consume meals from home ${ }^{(3,4)}$. It is during the summer months when foods from meal programmes are less readily available $^{(5)}$ and increased access to foods from home occurs. The unhealthy weight gain observed during summer may be attributed to this increase in availability and consumption of high-energy, low-nutrient-dense foods ${ }^{(6,7)}$.

Summer day camps (SDC), seasonal recreational programmes that provide child care and operate for 8-10 weeks during the summer ${ }^{(8)}$, are planned and organized by a wide variety of national franchises and community-based organizations. Out-of-school-time programmes serve a high-need population $^{(8)}$, with the majority of the approximately 14.3 million children who participate in SDC annually coming from low-income and minority households ${ }^{(9)}$. Therefore, SDC provide a great opportunity to improve the eating habits of this vulnerable population during the summer months.

The National Afterschool Association (NAA) released Standards for Healthy Eating for out-of-school-time programmes in April 2011, including after-school programmes and SDC, to ensure that foods and beverages consumed at these programmes support lifelong health of children ${ }^{(10)}$. These standards recommend children be provided a fruit or vegetable, water and beverages without caloric sweeteners daily, and no candy or sugar-based foods while 
attending one of these programmes ${ }^{(10)}$. In addition, the standards emphasize the importance of staff nutrition training and corresponding behaviours related to promoting healthy dietary behaviours of children, which include discussing the health benefits of foods with children and role modelling healthy eating ${ }^{(10)}$. Since many SDC do not provide meals or snacks, parents are responsible for packing foods and beverages; therefore, they too play a large role in the nutritional quality of foods. Studies exploring foods and beverages packed by parents in other settings (i.e. pre-school, elementary school) indicate that these meals do not meet nutrition standards ${ }^{(11)}$. The standards also recommend that parents be made aware of the healthy eating standards and be given guidelines on appropriate foods that support healthy eating objectives ${ }^{(10)}$.

The NAA standards represent an important step towards creating health-promoting environments during the summer; however, given their lack of guidelines specific to foods and beverages brought from home, they cannot be directly applied to SDC that do not provide meals or snacks. Therefore, the extent to which foods and beverages at SDC meet NAA standards currently cannot be assessed. The purpose of the present study was to describe: (i) the types of foods and beverages brought by children and staff to SDC; (ii) staff behaviours related to promoting nutrition; and (iii) the extent to which parents are being provided with education materials discussing nutrition standards. The research aim was to unveil the current SDC landscape surrounding healthy eating in an attempt to provide a foundation supporting the need for healthy eating standards applicable to all out-of-schooltime settings.

\section{Experimental methods}

\section{Participants}

Children attending and staff employed at four large-scale, community-based SDC in South Carolina participated in the current cross-sectional study as part of a 2-year nutrition and physical activity policy-level intervention. SDC were recruited based on pre-existing relationships. All children (K-5th grade) and staff participating in the SDC programme were eligible to be enrolled. Staff and parents were made aware of the nature of the study through the SDC website as well as informational flyers and staff trainings. Verbal informed consent was obtained from all subjects (parents and staff) and formally recorded. Staff, parents and children were given the option to opt out of any data collection. No staff or parent indicated they did not want to participate.

The study was conducted according to the guidelines laid down in the Declaration of Helsinki and all procedures involving human subjects were approved by the University of South Carolina's Institutional Review Board for the Protection of Human Subjects.

\section{Study procedures}

Each SDC programme began at 07.15 hours and ended at 18.00 hours Monday-Friday and lasted the entire summer (early June-mid August). A typical SDC day began with check-in time, which generally consisted of one to three large mixed-age group games (e.g. free play, field games). At 09.00 hours, the official start time for the SDC, children were grouped by grade level (e.g. 2nd and 3rd graders) and remained in these groups for the remainder of the day. A typical SDC schedule included two snack times and one lunch time scheduled for each group, lasting approximately $30 \mathrm{~min}$ for snack and $60 \mathrm{~min}$ for lunch; followed by physical activity time (e.g. sports games, hiking, waterbased activities); and enrichment activities (arts and crafts, reading). Across the SDC programmes the ratio of staff to children was 1:12.

Trained research assistants followed a single group (e.g. 2nd and 3rd graders) each day over $27 \mathrm{~d}$. Using a stratified sampling procedure, sub-samples of children from each grade level were selected and observed a minimum of two entire days at each SDC, ensuring food and beverage observations of at least $75 \%$ of children in any given grade level.

\section{Food and beverage measures}

The SDC did not provide food and beverages; therefore, staff and children brought their own foods and beverages for snacks and lunch in a single container (i.e. one lunchbox) each day. Information packets encouraged parents to pack water bottles for their child daily; and water was made available to the children throughout the day. At the beginning of the morning snack time on each observation day, children were asked to open their lunchboxes while a trained research assistant recorded what each child brought to eat and drink for the entire day. Each food and beverage item was recorded on one sheet, not differentiating between snack and lunch items. Children were asked to remain seated until everyone's foods and beverages were recorded during snack time to allow researchers to ask for clarification on any obscured items.

The method for observation of foods and beverages was based on existing direct observation protocols for child-care centres and elementary schools ${ }^{(11-13)}$ and modified for the SDC setting. Categories of foods and beverages are displayed in Table 1. Portion sizes were not recorded because children could bring any range of portion sizes in plastic bags or storage containers for the given items and quick estimation of portion sizes in differing sizes of containers is unreliable ${ }^{(14)}$. Because of this, a child's food was recorded as item present. For example, if a child brought two juice boxes, this was recorded as a child bringing a juice box (i.e. present). In addition to the type of food items brought, the total number of children observed was recorded which was used to calculate the percentage of children bringing an item.

Staff food nutritional quality was observed using direct observation over the duration of snack and lunch times 
Table 1 Classification categories and examples for child/staff foods and beverages brought to summer day camp (SDC), measured through direct observation, in four large-scale, community-based SDC in South Carolina, USA, summer 2011

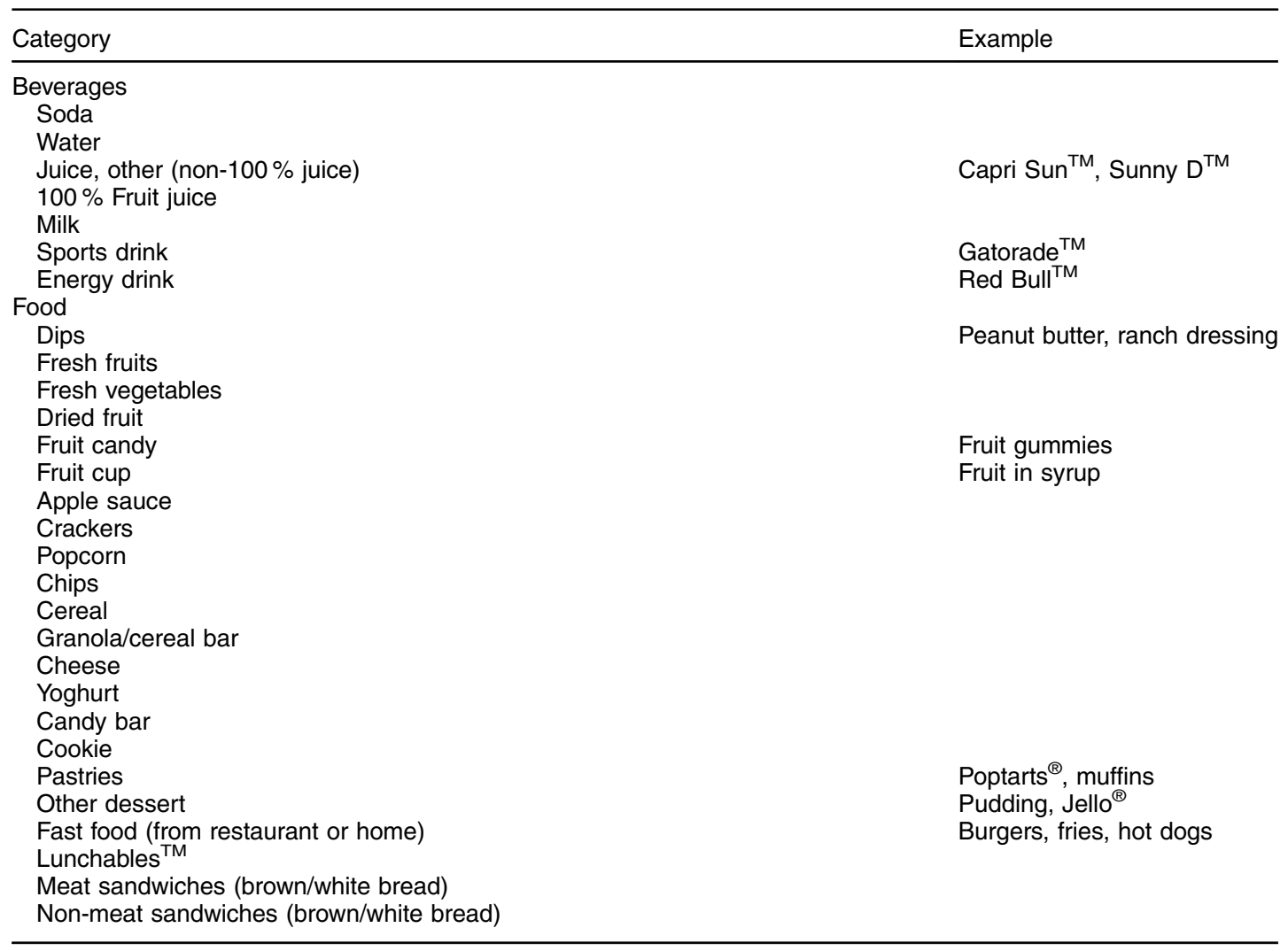

during each observation day. Staff nutrition observations were done during each meal time to account for staffing changes throughout the programme day. Staff food observations were recorded and classified the same as the child food categories with the addition of coffee and nut categories.

\section{Nutrition behaviour measures}

A systematic observation tool, Systematic Observation of Staff Promoting Activity and Nutrition (SOSPAN), was specifically developed for the present study to measure nutrition- and physical activity-promoting behaviours of staff in out-of-school-time programmes ${ }^{(15)}$. Only the nutrition-related behaviours are presented here. The tool was designed with two separate modules. The first was designed to measure nutrition-related behaviours during snack and meal times and the second module accounted for all instances where staff were observed eating or drinking outside snack and meal times. The nutrition behaviour observations consisted of: (i) 'discouragement of good eating behaviours' (i.e. staff speaking to children about their dislike of healthy foods); (ii) 'promotion of healthy eating' (i.e. staff speaking to children about the importance of eating healthily and prompting children to eat healthy foods); and (iii) modelling of good eating habits by eating foods on a regular basis that meet the body's nutrient requirements. Public health graduate research assistants $(n$ 4) underwent an initial training to establish agreement regarding staff behaviours. Stationed at a predefined location during meal and snack times, research assistants observed staff nutrition behaviours and recorded instances of staff discouraging or promoting good eating behaviours of the children. Staff members were observed over the entire duration of the snack and lunch times.

\section{Parent education measures}

The dissemination of parent nutrition education materials was measured through direct observation of parent and staff communications and through continual informal discussions with site directors regarding this material.

\section{Inter-observer reliability}

The inter-observer reliability of the food categories and staff behaviours was estimated using the weighted kappa statistic $\left(\kappa_{\mathrm{w}}\right)$ and percentage agreement. For foods, the $\kappa_{\mathrm{w}}$ coefficients ranged from 0.17 (other desserts) to 0.92 (apple sauce), for an average $\kappa_{\mathrm{w}}$ of 0.70 (median $0 \cdot 78$ ) suggesting moderate to high reliability on almost all of the items ${ }^{(12)}$. The percentage agreement across the food and beverage items ranged from $61 \%$ for popcorn to $98 \%$ for sports drinks, for an average percentage agreement of $91 \%$ (median $94 \%$ ). The $\kappa_{\mathrm{w}}$ coefficients for staff eating and drinking outside snack and lunch times were 1.00 and $0 \cdot 98$, respectively. Inter-rater reliability coefficients could 
not be obtained for staff nutrition promotion and discouragement behaviours due to the lack of frequency of these observations (see below for details).

\section{Statistical analysis}

Percentages ((food type/total staff or total children) $\times$ 100) in each food and beverage category were calculated separately for children and staff, using the statistical software package STATA/SE 11.0.

\section{Results}

\section{Child observations}

Observations of foods and beverages of 773 children were made across $27 \mathrm{~d}$ (total food and beverage occasions observed $=46$ ). The average number of children attending the SDC each day over the 10 weeks was 307 , with a range of $174-534$. The majority of children observed were under the age of 12 years. The number of children observed at each location varied based on weekly enrolment numbers. The average number of children observed in a single group was $10 \cdot 9$, with a range of 5-42. Percentages of foods and beverages brought by children are shown in Table 2. For beverages brought, less than half of the children were observed with water, $46 \%$ with non-100\% juices and $14 \%$ with sports drinks. Eighty per cent of children brought salty snack foods (e.g. chips, crackers), while only $26 \%$ and $2 \%$ brought fruits and vegetables, respectively. Fruit candy (e.g. fruit gummies, roll ups; $16 \%$ ) and cookies (24\%) were observed most often. Twenty per cent of children brought Lunchables ${ }^{\mathrm{TM}}$

Table 2 Percentage of foods and beverages brought by children ( $n$ 773) and staff (126 observations) across $27 \mathrm{~d}$ at four large-scale, community-based summer day camps in South Carolina, USA, summer 2011

\begin{tabular}{|c|c|c|}
\hline Category & Child percentage & Staff percentage \\
\hline \multicolumn{3}{|l|}{ Beverages } \\
\hline Soda/pop & 3.4 & $10 \cdot 0$ \\
\hline Water & 41.9 & 63.5 \\
\hline Juice $100 \%$ & 3.4 & 1.6 \\
\hline Juice, other (non-100\% juice, e.g. Capri Sun ${ }^{\mathrm{TM}}$, juice boxes) & 45.9 & 14.0 \\
\hline Milk & 0.7 & 0.0 \\
\hline Sports D & $13 \cdot 6$ & $15 \cdot 8$ \\
\hline Energy D & 0.3 & 0.0 \\
\hline \multicolumn{3}{|l|}{ Fruits and vegetables } \\
\hline Vegetable & $2 \cdot 2$ & 8.6 \\
\hline Fruit fresh & $26 \cdot 1$ & 29.8 \\
\hline Fruit dried & $2 \cdot 8$ & $5 \cdot 2$ \\
\hline Fruit cup & $9 \cdot 3$ & 4.2 \\
\hline Apple sauce & $8 \cdot 1$ & $4 \cdot 8$ \\
\hline \multicolumn{3}{|l|}{ Sweeteners } \\
\hline Fruit candy & $15 \cdot 6$ & 4.3 \\
\hline Cereal & 1.8 & 3.4 \\
\hline Granola/cereal bar & $12 \cdot 0$ & 3.6 \\
\hline Candy bar & 5.9 & 2.0 \\
\hline Cookie & 23.5 & 10.5 \\
\hline Pastries & $15 \cdot 1$ & $10 \cdot 3$ \\
\hline Other dessert & $9 \cdot 6$ & 5.9 \\
\hline \multicolumn{3}{|l|}{ Salty foods } \\
\hline Cracker & 24.4 & $12 \cdot 4$ \\
\hline Popcorn & 3.0 & $4 \cdot 3$ \\
\hline Chips & 52.5 & 48.0 \\
\hline \multicolumn{3}{|l|}{ Added 'visible' fats } \\
\hline Dips & 3.5 & 2.4 \\
\hline \multicolumn{3}{|l|}{ Dairy } \\
\hline Cheese & $5 \cdot 3$ & $2 \cdot 1$ \\
\hline Yoghurt & $5 \cdot 8$ & $2 \cdot 6$ \\
\hline \multicolumn{3}{|l|}{ Pre-packaged foods } \\
\hline Fast food & $7 \cdot 2$ & $9 \cdot 0$ \\
\hline Lunchables $^{\mathrm{TM}}$ & 19.5 & $4 \cdot 1$ \\
\hline \multicolumn{3}{|l|}{ Sandwiches } \\
\hline Brown bread with meat & 5.4 & 0.1 \\
\hline White bread with meat & $18 \cdot 3$ & $17 \cdot 1$ \\
\hline Brown bread non-meat & $6 \cdot 8$ & 5.7 \\
\hline White bread non-meat & $17 \cdot 7$ & 3.0 \\
\hline Meat sandwich (bread type not provided) & - & $9 \cdot 3$ \\
\hline Non-meat sandwich (bread type not provided) & - & 11.6 \\
\hline Nuts & _ & 0.6 \\
\hline Coffee & - & 0.6 \\
\hline Other (pasta, eqgs) & 14.5 & 14.1 \\
\hline
\end{tabular}

Categories may not total $100 \%$ since multiple food items were allowed for each meal/snack (i.e. water and juice). 
meals and $48 \%$ brought sandwiches (18.3\%, white bread with meat; $17.7 \%$, white bread without meat; $5 \cdot 4 \%$, brown bread with meat; $6 \cdot 8 \%$, brown bread without meat).

\section{Staff observations}

Observations of 126 staff foods and beverages and 315 staff behaviours were made across $27 \mathrm{~d}$. The average number of staff observed was $2 \cdot 2$ with a range of $1-10$. Percentages of foods and beverages brought by staff are shown in Table 2. Water (64\%) was the most prevalent beverage observed for staff. Fresh fruit and vegetables were observed $30 \%$ and $9 \%$ of the time, respectively. Sweeteners (i.e. foods with added sugar), consisting of fruit candy/gummies, candy bars, granola/cereal bars, cereal, cookies, pastries and other desserts, were observed $40 \%$ of the time. Chips were the most prevalent salty snack observed (48\%), while dairy products were observed only $5 \%$ of the time. Pre-packaged foods including Lunchables ${ }^{\mathrm{TM}}$ and fast foods were observed $13 \%$ of the time. Meat and non-meat sandwiches (e.g. peanut butter) were observed $47 \%$ of the time for staff.

Staff nutrition behaviours, measured using the SOSPAN tool, indicate that staff promotion of good nutrition habits was observed less than $1 \%$ of the total observation time (i.e. duration of meal/snack time). Staff were observed eating or drinking $3.4 \%$ of the time outside meal time. Forty-two per cent of this observed time staff consumed low-nutrient-dense foods such as fast food, desserts, pastries and candies. Soda and sports drinks were observed $38 \%$ of the time and beverages in fast-food containers were observed $34 \%$ of the time.

Finally, the SDC programmes did not provide parents with nutrition materials regarding the nutrition standards.

\section{Discussion}

Based on our findings, current foods and beverages brought from home to SDC do not support the healthy eating recommendations set forth by the NAA and staff do not regularly promote healthy nutrition habits. Overall, few children brought fruits, vegetables and water and over half the children brought items considered as low-nutrientdense foods, such as pre-packaged crackers, popcorn, chips and non-100\% fruit juices. Similar results were found for the types of foods staff brought to the SDC. With over 14 million children attending SDC, this setting provides an opportunity to promote healthy nutrition habits of children and opportunities to model healthy eating habits by staff. Thus, it appears that this sample of SDC are not supporting healthy nutrition habits of either staff or the children attending.

Child dietary habits are among the factors contributing to rapid weight gain during summer months ${ }^{(1,6)}$. As school meals offering more nutrient-dense foods are unavailable during summer months, access to high-energy, lownutrient-dense foods often increases ${ }^{(1-4)}$. Our findings, consistent with school studies, reveal that meals brought from home contain few fruits and vegetables and primarily consist of low-nutrient-dense foods and beverages ${ }^{(6,16-18)}$.

Our findings indicated that no information was provided by the SDC to the parents regarding healthy food and beverage recommendations and options. The ability of SDC staff to regulate the foods and beverages brought to camp by children may be limited due to anticipated negative parental reaction. To increase the nutritional quality of foods and beverages brought by children to SDC, programmes should address parental perceived barriers to packing healthier foods, such as cost ${ }^{(19)}$ and child food preference $^{(7)}$. SDC should increase parent awareness of healthy eating standards and the types of low-cost foods that meet these standards through informational sessions, handouts, guidelines and advice. Parental education coupled with child nutrition activities has been shown to be effective in changing parental packing behaviours ${ }^{(11)}$. SDC could seek partnerships with community entities, such as local grocery stores and nutrition experts, to help provide discounts/incentives (e.g. coupons) for healthy food and beverage purchases.

Additionally, staff need to be made aware of current standards and be provided with opportunities to learn nutrition promotion skills and tips on packing their own healthy foods and beverages. SDC directors may benefit from the development of nutrition guidelines for staff that strongly encourage staff to bring foods and beverages that meet existing guidelines and refrain from bringing foods that may promote unhealthy eating behaviours (i.e. sweet foods, potato chips, fast food). Regulations may be set on beverages allowed. For instance, if a staff member brings a beverage other than water it must be in an opaque bottle so that it is not identifiable. To improve upon modelling of good nutrition habits, SDC directors can require that all staff sit and eat foods and beverages with the campers. This is also an opportune time for staff to discuss the health benefits of eating a healthy diet.

Lastly, considering that the length of child attendance at SDC varies from that of many other out-of-school-time programmes (i.e. all day and overnight), the appropriateness of the current NAA standards for this setting should be reassessed. Guidelines on what foods and beverages children and staff are allowed to bring to SDC may be more beneficial in promoting healthy eating in environments where meals and snacks are not provided.

Potential limitations of the study include low interobserver reliability values for some food and beverage items. Observed food and beverage items were placed into categories previously developed for child care and school settings ${ }^{(11-13)}$. Staff food and beverage observations were categorized using the same method, thus resulting in the need for additional categories (e.g. coffee and nuts). Categories that were rarely observed potentially resulted in low $\kappa_{\mathrm{w}}$ coefficients; however, overall inter-observer percentage agreement among food and beverage items and categories 
resulted in moderate to high agreement. Another limitation of the present study was the inability to observe all foods and beverages for any individual staff member over the programme duration. To ensure accurate representation of the foods and beverages brought to camp by staff, any instances of staff eating or drinking outside designated meal times was recording through systematic observation.

\section{Implications for research and practice}

Based on findings of the current study, children are not bringing foods and beverages to SDC that support the NAA healthy eating standards, raising concerns about their appropriateness for all out-of-school-time settings. While nutrition standards have great intention, in order to achieve the goals set forth by the standards, efforts need to target professional development opportunities for staff, as well as working with parents to assist in identifying ways to increase the nutritional content of snacks and lunches packed for their child.

\section{Acknowledgements}

Acknowledgements: The authors would like to extend their appreciation to the SDC staff, children and parents who made this study possible. Financial support: The project described was supported by Award Number R21HL106020 from the National Heart, Lung, and Blood Institute. Its content is solely the responsibility of the authors and does not necessarily represent the official views of the National Heart, Lung, and Blood Institute or the National Institutes of Health. The National Heart, Lung, and Blood Institute had no role in the design, analysis or writing of this article. Conflict of interest: None. Authorship: All authors contributed extensively to the presented work. F.T. collected/analysed data and wrote paper; M.W.B. conceived the project and supervised all research components; S.J. and G.T.-M. provided insight/feedback throughout research process. Ethics of buman subject participation: The study was conducted according to the guidelines laid down in the Declaration of Helsinki and all procedures involving human subjects were approved by the University of South Carolina's Institutional Review Board for the Protection of Human Subjects.

\section{References}

1. von Hippel PT, Powell B, Downey DB et al. (2007) The effect of school on overweight in childhood: gain in body mass index during the school year and during summer vacation. Am J Public Health 97, 696-702.

2. Crepinsek MK, Gordon AR, McKinney PM et al. (2009) Meals offered and served in US public schools: do they meet nutrition standards? J Am Diet Assoc 109, 2 Suppl, S31-S43.
3. Gordon AR, Crepinsek MK, Briefel RR et al. (2009) The third School Nutrition Dietary Assessment Study: summary and implications. J Am Diet Assoc 109, Suppl. 2, S129-S135.

4. Johnston CA, Moreno JP, El-Mubasher A et al. (2012) School lunches and lunches brought from home - a comparative analysis. Child Obes 8, 364-368.

5. US Department of Agriculture, Food and Nutrition Service (2012) Summer Food Service Program. http://www.fns. usda.gov/cnd/summer/ (accessed March 2012).

6. Gillis L, McDowell M \& Bar-Or O (2005) Relationship between summer vacation weight gain and lack of success in a pediatric weight control program. Eat Behav 6, 137-143.

7. Dowda M, Ainsworth BE, Addy CL et al. (2001) Environmental influences, physical activity, and weight status in 8- to 16-year-olds. Arch Pediatr Adolesc Med 155, 711-717.

8. Afterschool Alliance (2013) Afterschool Essentials: Research and Polling Afterschool Issue Overview. http://www. afterschoolalliance.org/researchFactSheets.cfm (accessed May 2014).

9. Afterschool Alliance (2009) America After 3PM. Special Report on Summer: Missed Opportunities, Unmet Demand. http://www.afterschoolalliance.org/documents/Special_Report_ on_Summer_052510.pdf (accessed October 2011).

10. National Afterschool Association (2011) National Afterschool Association Standards for Healthy Eating and Physical Activity. http://www.naaweb.org/downloads/resources/HEPAStandards 8-4-11final.pdf (accessed May 2011).

11. Sweitzer SJ, Briley ME, Roberts-Gray C et al. (2010) Lunch is in the bag: increasing fruits, vegetables, and whole grains in sack lunches of preschool-aged children. J Am Diet Assoc 110, 1058-1064.

12. Economos CD, Sacheck JM, Kwan Ho et al. (2008) Schoolbased behavioral assessment tools are reliable and valid for measurement of fruit and vegetable intake, physical activity, and television viewing in young children. $J$ Am Diet Assoc 108, 695-701.

13. Ball SC, Benjamin SE \& Ward DS (2007) Development and reliability of an observation method to assess food intake of young children in child care. J Am Diet Assoc 107, 656-661.

14. Yuhas JA, Bolland JE \& Bolland TW (1989) The impact of training, food type, gender, and container size on the estimation of food portion sizes. J Am Diet Assoc 89, 1473-1477.

15. Weaver R, Beets M, Webster C et al. (2014) System for Observing Staff Promotion of Activity and Nutrition (SOSPAN). J Phys Act Health 11, 173-185.

16. Briley M, Ranjit N, Holescher DM et al. (2012) Unbundling outcomes of a multilevel intervention to increase fruit, vegetables, and whole grains parents pack for their preschool children in sack lunches. Am J Health Educ 43 , 135-142.

17. Johnson CM, Bednar C, Kwon J et al. (2009) Comparison of nutrient content and cost of home-packed lunches to reimbursable school lunch nutrient standards and prices. $J$ Child Nutr Manag 33, 1-8.

18. Rainville AJ (2001) Nutritional quality of reimbursable school lunches compared to lunches brought from home in elementary schools in two southeastern Michigan districts. J Child Nutr Manag 25, 13-18.

19. Mushi-Brunt C, Haire-Joshu D \& Elliot M (2007) Food spending behaviors and perceptions are associated with fruit and vegetable intake among parents and their adolescent children. J Nutr Educ Behav 39, 26-30. 